\title{
A minimally invasive method to mend a broken heart
}

Heartache is common in love, but also in biomedicine. In a new report from Nature Materials, a minimally invasive method for delivering engineered tissue could help improve treatment after a heart attack, among other ailments (Nat. Mater. doi:10.1038/nmat4956, published online 14 August 2017).

Methods to build complex human tissue for regenerative medicine are getting more sophisticated each year, but delivery still happens, by and large, the old fashioned way. "When we started this project four years ago," says Milica Radisic, senior author and head of the Laboratory for Functional Tissue Engineering at the University of Toronto, "the only way to get tissue in the body was through an invasive procedure, and we thought, wouldn't it be cool to deliv- er tissues into patients without having to cut anyone open."

Miles Montgomery, co-first author on the new paper, worked with his colleagues in Radisic's lab to design a novel tissue scaffold system that is flexible enough to slip into the body through a needle injection, but solid enough to support patches of tissue composed of engineered cardiac cells. The first step was designing a biomaterial with just the right balance of elasticity and mechanical strength, which Montgomery accomplished via trial-and-error in vitro tests. "There wasn't really any literature to base this on," says Montgomery, "so I had to design wide and slowly narrow down to something we wanted."

After some adjustments to ensure tissue patches wouldn't slide off the scaffold during injections, the team put the injectable system to the test, treating rat models of myocardial infarction. Compared with non-treated rats, all of the parameters the team looked at, including contraction and relaxation ability of the heart, were significantly improved with the injectable cardiac patches.

With an aim to evaluate translational potential, the Radisic lab also tested injectable tissue patches in pig models using existing laparoscopic tools and techniques, showing functional delivery of target-specific tissue to the heart, liver, and aorta. The team will need to run more preclinical tests, but they're hopeful their new injectable system will provide a minimally invasive option to deliver tissues for a variety of human conditions, heart-wrenching or otherwise. 